TITLE:

\title{
Mechanical characterization of nanoporous Au modified with self- assembled monolayers
}

\section{AUTHOR(S):}

Miyazawa, Naoki; Ishimoto, Junya; Hakamada, Masataka; Mabuchi, Mamoru

\section{CITATION:}

Miyazawa, Naoki ...[et al]. Mechanical characterization of nanoporous Au modified with self-assembled monolayers. Applied Physics Letters 2012, 109(26): 261905.

ISSUE DATE:

2012-12-26

URL:

http://hdl.handle.net/2433/237612

\section{RIGHT:}

(c) 2016 Author(s). The following article appeared in 'Appl. Phys. Lett. 109, 261905 (2016)' and may be found at https://aip.scitation.org/doi/abs/10.1063/1.4972780.; The full-text file will be made open to the public on 26 December 2017 in accordance with publisher's 'Terms and Conditions for Self-Archiving'. 


\title{
Mechanical characterization of nanoporous Au modified with self-assembled monolayers
}

\author{
Naoki Miyazawa, ${ }^{\text {a) }}$ Junya Ishimoto, ${ }^{\text {b) }}$ Masataka Hakamada, and Mamoru Mabuchi \\ Graduate School of Energy Science, Kyoto University, Yoshidahonmachi, Sakyo, Kyoto 606-8501, Japan
}

(Received 12 September 2016; accepted 8 December 2016; published online 28 December 2016)

\begin{abstract}
The surface of nanoporous Au was modified with self-assembled monolayers (SAMs) of 6-mercapto-1-hexanol and the hardness tests were performed on the SAM-modified and non-modified nanoporous Au to investigate the effects of SAM modification on the mechanical properties of nanoporous $\mathrm{Au}$. In addition, the origin of the chemomechanical effects was investigated by first principles shear test simulations on an $\mathrm{Au}-\mathrm{S}$ alloy. The SAM-modified nanoporous Au showed lower hardness than the non-modified nanoporous Au. The loading rate dependence tests showed that the activation volume was low for both, indicating that events of a short range play an important role in deformation of nanoporous Au, regardless of whether the nanoporous Au was modified with SAMs. It was suggested from the simulations that the lower hardness for the SAM-modified nanoporous $\mathrm{Au}$ is because movement of dislocation endpoints at the surface is facilitated by chemical effects of Au-S bonding. Published by AIP Publishing. [http://dx.doi.org/10.1063/1.4972780]
\end{abstract}

Nanoporous metals have received a lot of attention because they exhibit remarkable properties that are not observed in bulk metals. For example, nanoporous Au catalyzes the oxidation of $\mathrm{CO}^{1}$ whereas bulk $\mathrm{Au}$ does not. Piezoelectricity in some gaseous ${ }^{2}$ and electrochemical ${ }^{3}$ environments is also an interesting feature of nanoporous metals and can be applied in sensors, actuators, and other applications. Furthermore, the strength of nanoporous metals is as high as the ideal strength ${ }^{4,5}$ and strongly depends on its ligament or pore size, ${ }^{6-8}$ whereas the strength of conventional porous metals with pore sizes in the millimeter and micrometer range does not depend on the ligament or pore size. The sizes of the ligaments of nanoporous metals are much lower than the sizes of the Frank-Read sources that provide sites for dislocation nucleation, and dislocations cannot be nucleated inside the ligaments. Hence, plastic deformation of nanoporous metals is likely to be closely connected with events of the short range such as the nucleation of dislocations at the surface. ${ }^{9,10}$ This suggests that the strength of a nanoporous metal depends on its surface states. ${ }^{10}$ To date, the mechanical properties of nanoporous metals have been investigated; ${ }^{4-8,11}$ however, there is still insufficient understanding about the effects of surface states on the mechanical properties of nanoporous metals.

Recently, self-assembled monolayers (SAMs) have been widely used as an efficient method to modify the physical and chemical properties of solid surfaces. SAM-modified surfaces have been applied for biosensing, ${ }^{12}$ corrosion inhibition, ${ }^{13}$ wetting inhibition, ${ }^{14}$ and nanolithography. ${ }^{15}$ There have been many studies that have investigated the mechanical properties of SAM-modified Au, ${ }^{16-21}$ but most of them do not describe the mechanical properties of $\mathrm{Au}$, but SAMs. ${ }^{16-20}$ Recently, it was found that plastic deformation

\footnotetext{
a) Author to whom correspondence should be addressed. Electronic mail: miyazawa.naoki.37c@st.kyoto-u.ac.jp

${ }^{b)}$ Present address: Toyota Motor Corporation, Toyota-Cho, Toyota City, Aichi 471-8571, Japan.
}

of Au occurs more easily in SAM-modified Au films than in unmodified Au films owing to chemomechanical effects. ${ }^{21}$ In the present work, the mechanical properties of nanoporous $\mathrm{Au}$ modified by SAMs were investigated using hardness tests. Chemomechanical effects may be enhanced for nanoporous $\mathrm{Au}$, compared with the Au film, because of more specific surface area of nanoporous Au. In addition, firstprinciples shear test simulations were performed to investigate the effects of the $\mathrm{S}$ atom on the dislocation nucleation and to help understand the origins of the chemomechanical effects by SAM modification.

$\mathrm{Au}(>99.9$ mass \%) and $\mathrm{Ag}(>99.9$ mass \%) ingots were arc-melted together in an Ar atmosphere to prepare a precursor $\mathrm{Au}_{0.3} \mathrm{Ag}_{0.7}$ ingot. After homogenization at $1173 \mathrm{~K}$ for $24 \mathrm{~h}$ in an Ar atmosphere and subsequent cold rolling, nanoporous $\mathrm{Au}$ with an average ligament size of $50 \mathrm{~nm}$ was formed by free corrosion (without any electrochemical potential) of the alloy at $293 \mathrm{~K}$ for $24 \mathrm{~h}$ in $69 \mathrm{wt} . \% \mathrm{HNO}_{3}$. The nanoporous Au was rinsed in deionized water and ethanol. To modify the nanoporous $\mathrm{Au}$ with SAM, the nanoporous $\mathrm{Au}$ samples were immersed in $1.0 \mu \mathrm{M}$ ethanolic solution of 6-mercapto-1-hexanol (MHO), which has been frequently used for immobilization of DNA and laccase,,$^{22,23}$ at $251 \mathrm{~K}$ for $3 \mathrm{~h}$. After the immersion, the samples were rinsed thoroughly with ethanol, distilled water, and dried in air.

After the cross sections of the SAM-modified nanoporous $\mathrm{Au}$ samples were carefully polished by gentle manual polishing after embedding in epoxy-resin (with a Teflon tape covering the samples to prevent resin infiltration into nanopores), the hardness tests were performed on the polished samples at room temperature. The preliminary tests on nanoporous $\mathrm{Au}$ showed that the polishing did not alter the mechanical response during indentation. An apparatus equipped with a diamond Vickers tip was used for the hardness tests. The tip was brought into contact with the sample and indented at a constant loading rate of $1.324 \mathrm{mN} / \mathrm{s}$. The load was kept constant at $30 \mathrm{mN}$ for $10 \mathrm{~s}$ and then the tip was retracted. The tests were performed 10 times for each sample 
(a)
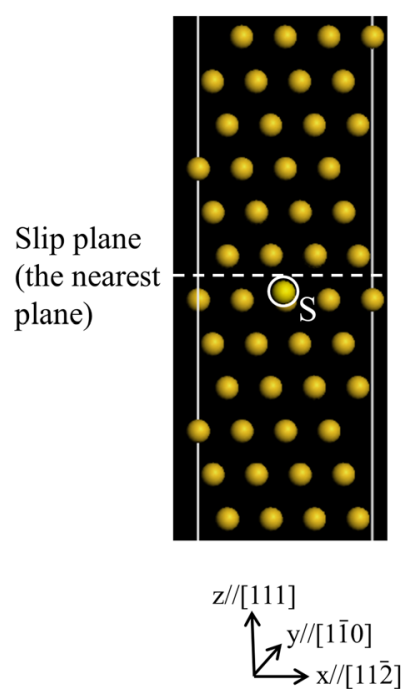

(b)
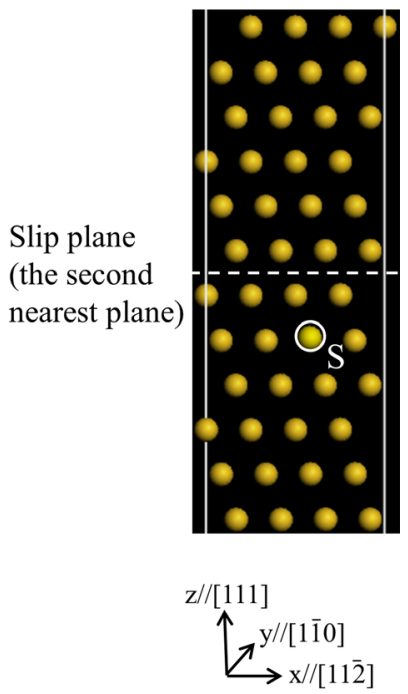

FIG. 1. Au-S cell models for first principles shear test calculations; (a) $\mathrm{Au}-\mathrm{S}$ cell for sharing at the nearest plane and (b) Au-S cell for shearing at the second nearest plane. S shows a $\mathrm{S}$ atom.

and the average and standard deviation of the hardness value were obtained from the load-displacement curves. In addition, the hardness tests at loading rates of $0.378-13.24 \mathrm{mN} / \mathrm{s}$ were performed to estimate the dependence of the hardness on the loading rate.

First-principles calculations were performed using the Cambridge Serial Total Energy Package (CASTEP), ${ }^{24}$ in which the density functional theory (DFT) ${ }^{25,26}$ was used with a plane-wave basis set. The Perdew-Wang (PW91) version of the generalized gradient approximation was used to represent the exchange-correlation functional in the DFT. Ultrasoft pseudopotentials ${ }^{27}$ were used for all the elements in the calculations. The plane-wave energy cutoff was $320 \mathrm{eV}$. The Brillouin zone was sampled using the $3 \times 5 \times 1$ Monkhorst-Pack k-point grid $^{28}$ for all the models, and the Gaussian smearing was set with a width of $0.1 \mathrm{eV}$. A schematic illustration of a supercell used for the calculations is shown in Fig. 1. A cell for a pure Au model consisted of 12 layers in the [111] direction and the unit cell contained 48 $\mathrm{Au}$ atoms. The size of the unit cell was $10.0 \times 5.8 \times 59.2 \AA$. A vacuum slab with a width of $15 \AA$ was added to avoid interactions with the periodic image and to relax the cell in the [111] direction. A cell for a Au-S alloy model was prepared by substituting one Au atom with one $\mathrm{S}$ atom, in which the slip planes for the shear tests were nearest to the $S$ atom (first nearest plane) and second nearest to the $\mathrm{S}$ atom (second

nearest plane), as shown in Fig. 1. All atomic positions were optimized in accordance with Hellman-Feynman forces of less than $0.01 \mathrm{eV}^{-1}$. These conditions provided good convergence. The general stacking fault energy (GSFE) has been investigated by first-principles shear test calculations for estimating nucleation or movement capacity of dislocations. ${ }^{29-33}$ The simulations were performed by cutting a perfect crystal with two free surfaces and displacing the two parts relative to each other on the fault vector, $x$, in a slip plane. The GSFE was calculated as the difference in total energies between the two supercells designed to simulate faults with the $x=0$ and $x \neq 0$ vectors for the basal plane of $\mathrm{Au}:[11 \overline{2}](111)$ slip system. The atomic positions were relaxed only in the direction perpendicular to the slip plane. The effects of solute atoms on the GSFE can be classified into strain effects and chemical effects. ${ }^{34}$ A strained model was used to assess the strain and chemical effects based on the studies of the grain boundary segregation. ${ }^{35-39}$ The strained model was the cell model in which a $S$ atom in a $\mathrm{Au}-\mathrm{S}$ alloy model was replaced by a Au atom, keeping the same atomic configuration in the Au alloy model without further relaxation. The GSFEs related to strain and chemical effects can be given by

$$
\begin{aligned}
& E_{\text {strain effect }}=E_{\text {strained }}-E_{\text {pure }}, \\
& E_{\text {chem effect }}=E_{\text {alloy }}-E_{\text {strained }},
\end{aligned}
$$

where $E_{\text {strain effect }}$ and $E_{\text {chem effect }}$ are the GSFEs related to strain effects and to chemical effects, respectively, and $E_{\text {pure }}$, $E_{\text {alloy }}$, and $E_{\text {strained }}$ are the GSFEs of the pure Au model, the $\mathrm{Au}-\mathrm{S}$ model, and the strained model, respectively.

Figure 2 shows scanning electron microscopy images of the nanoporous $\mathrm{Au}$ and the SAM-modified nanoporous $\mathrm{Au}$. The ligament length was approximately $50 \mathrm{~nm}$ for both the nanoporous $\mathrm{Au}$ and the SAM-modified nanoporous $\mathrm{Au}$, and there was hardly any difference in the ligament length between the two. Thus, the SAM modification did not affect the porous structure.

The results of the hardness tests at a loading rate of $1.324 \mathrm{mN} / \mathrm{s}$ are shown in Fig. 3 for the nanoporous Au and the SAM-modified nanoporous Au. Clearly, the hardness of the SAM-modified nanoporous Au was lower than that of the non-modified Au. The variation of the hardness as a function of the loading rate is shown in Fig. 4. The hardness of bulk Au shows no dependence on the loading rate under the investigated test conditions. However, the hardness of both the SAM-modified and the non-modified nanoporous Au showed a large dependence on the loading rate. The activation volume can be given by ${ }^{40}$
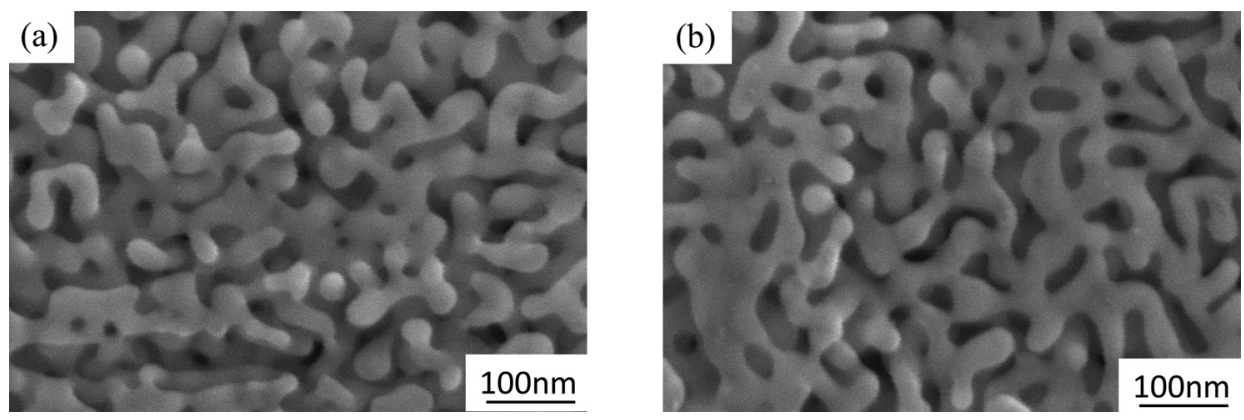

FIG. 2. Scanning electron microscopy images of (a) nanoporous Au and (b) SAM-modified nanoporous Au. The average ligament size is $50 \mathrm{~nm}$. There is hardly any difference in the ligament length between the two. 


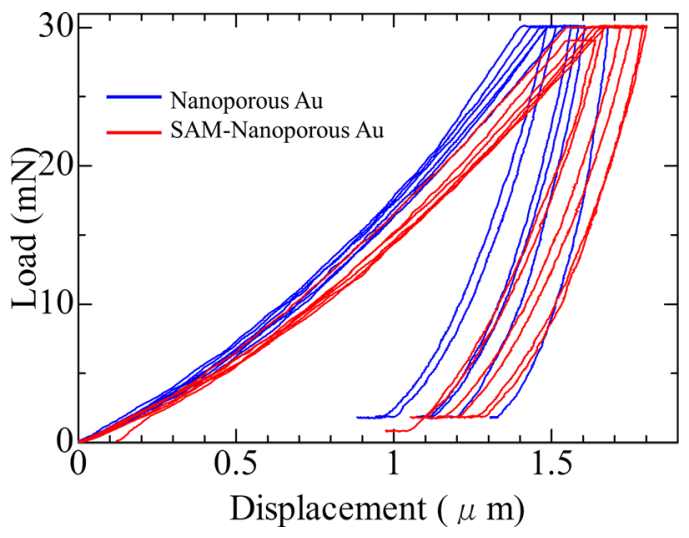

FIG. 3. Results of the hardness tests at a loading rate of $1.324 \mathrm{mN} / \mathrm{s}$ for nanoporous $\mathrm{Au}$ and SAM-modified nanoporous Au. The hardness of the SAM-modified nanoporous Au is lower than that of the non-modified one.

$$
v^{*}=\sqrt{3} k T\left(\frac{\partial \ln \dot{\varepsilon}}{\partial \sigma}\right)=3 \sqrt{3} k T\left(\frac{\partial \ln \dot{\varepsilon}}{\partial H}\right),
$$

where $v^{*}$ is the activation volume, $k$ is the Boltzmann constant, $\dot{\varepsilon}$ is the strain rate, $T$ is the absolute temperature, $\sigma$ is the flow stress, and $H$ is the hardness, which is assumed to be three times the flow stress. The activation volume was $86 b^{3}$ for the non-modified nanoporous $\mathrm{Au}$ and $146 b^{3}$ for the SAM-modified nanoporous Au, where $b$ is the Burgers vector of Au. Taking the experimental error into consideration, the difference in the activation volume between the nonmodified nanoporous Au and the SAM-modified is negligible. Recently, Jin et al. ${ }^{41}$ investigated deformation behavior of nanoporous Au by compressive tests and they showed that the strain rate sensitivity of stress depended on the strain, indicating that the activation volume depended on the strain. The activation volumes obtained in the present work corresponded to the maximum value of activation volume of nanoporous Au in the work by Jin et al. ${ }^{41}$ (=about $90 b^{3}$ ). It is noted that the activation volumes of nanoporous $\mathrm{Au}$ are lower than that for the dislocation forest hardening $\left(\approx 1000 b^{3}\right)$.

Dislocations glide over distances much larger than the ligament size during deformation in nanoporous $\mathrm{Au}^{41}$

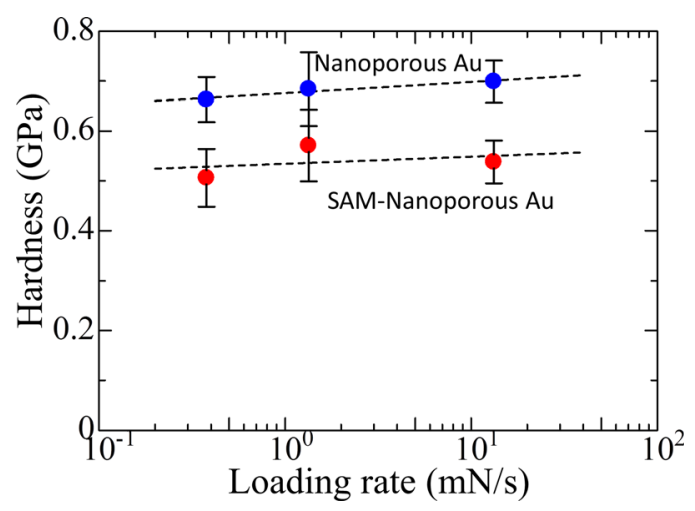

FIG. 4. Variations of hardness as a function of loading rate for nanoporous $\mathrm{Au}$ and SAM-modified nanoporous Au. From the results of the rate dependence, the activation volume is estimated to be $86 b^{3}$ for the non-modified nanoporous $\mathrm{Au}$ and $146 b^{3}$ for the SAM-modified nanoporous $\mathrm{Au}$, where $b$ is the Burgers vector of Au. The activation volumes are lower than that for the dislocation forest hardening $\left(\approx 1000 b^{3}\right)$. indicating that events of a long range play an important role in deformation of nanoporous Au. However, the fact of the low activation volumes suggests that events of a short range as well as those of a long range play an important role in deformation of nanoporous Au. Dislocations are not nucleated inside the ligaments of a nanoporous metal because no Frank-Read sources exist in the ligaments. Hence, dislocation nucleation at a surface may play a critical role in the plastic deformation of nanoporous Au. On the other hand, moving dislocations have an interaction with adsorbates at the surface. ${ }^{42}$ Thus, the lower hardness of the SAM-modified nanoporous Au may be related to an interaction between moving dislocations and surfaces. The stresses for nucleation and movement of dislocations at a surface are of a short range, resulting in low activation volumes, as shown in Fig. 4. Hence, it is worthwhile to investigate effects of a $\mathrm{S}$ atom on the nucleation and movement of dislocations. In the SAM-modified nanoporous $\mathrm{Au}, \mathrm{Au}$ atoms located at the surface are bonded to a S atom of a SAM that is located out of the Au surface. ${ }^{43}$ It is difficult to strictly simulate the nucleation and movement of a dislocation in the atomic configuration by first principles calculations. The atomic configuration of the cells used for first principles shear test simulations is different from that of the SAM-modified nanoporous $\mathrm{Au}$; however, some trends about the effects of a $S$ atom on the nucleation and movement of a dislocation can be obtained by the shear test simulations. Figure 5(a) shows GSFE curves for $\mathrm{Au}$ and $\mathrm{Au}-\mathrm{S}$ cells by first principles shear test simulations. Note that the ultimate stacking fault energy (USFE) for slip at the nearest plane for the Au-S cell was much lower than that for the Au cell. On the other hand, a reduction in USFE for slip at the second nearest plane for the $\mathrm{Au}-\mathrm{S}$ cell was minor. Hence, $\mathrm{Au}-\mathrm{S}$ bonding is suggested to make the nucleation and movement of a dislocation easy. Jin et $a l .{ }^{41}$ showed that the strain rate dependence of stress increased with the strain, which indicates that events of a short range are mainly related to the dislocation movement, not the dislocation nucleation. Therefore, it is suggested that adsorbates are removed by the SAM modification; in addition, $\mathrm{Au}-\mathrm{S}$ bonding facilitates the movement of dislocation endpoints, which lead to the lower hardness of the SAMmodified nanoporous Au.

Figure 5(b) shows the GSFE curves related to strain effects and chemical effects for shearing at the nearest plane of the Au-S cell. The GSFE relating to the strain effects of the $\mathrm{Au}-\mathrm{S}$ model corresponded to the GSFE of the pure $\mathrm{Au}$ model, and the USFE of the former $\left(=46.0 \mathrm{~mJ} / \mathrm{m}^{2}\right)$ almost agreed with that of the latter $\left(=49.4 \mathrm{~mJ} / \mathrm{m}^{2}\right)$. Thus, the strain effects of Au-S had little effect on the GSFE. On the other hand, the chemical effects of Au-S decreased the GSFE. The trend of the chemical effects is hardly affected by the atomic configuration. Therefore, a reduction in USFE by the Au-S bonding is suggested to be due to the chemical effects of $\mathrm{Au}-\mathrm{S}$ bonding, despite the limitation of the present calculation scheme. The Au-S bond may be strong because $\mathrm{Au}$ and $\mathrm{S}$ atoms are covalently bonded. ${ }^{44}$ However, Au-Au bonds around a $\mathrm{S}$ atom probably become weakened because charge transfer occurs from $\mathrm{Au}$ atoms to a $\mathrm{S}$ atom owing to the larger electronegativity of $\mathrm{S}$. Hence, the breaking of the weakened $\mathrm{Au}-\mathrm{Au}$ bond may occur preferentially because not 
(a)

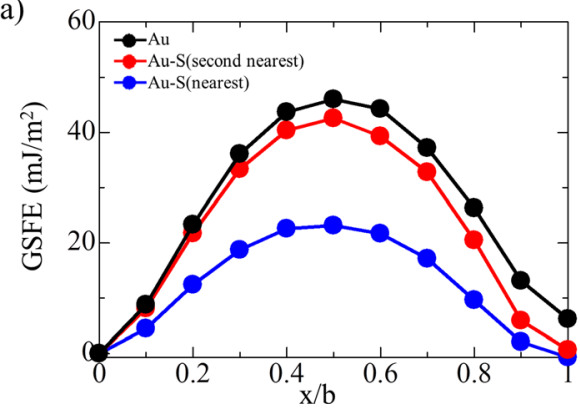

(b)

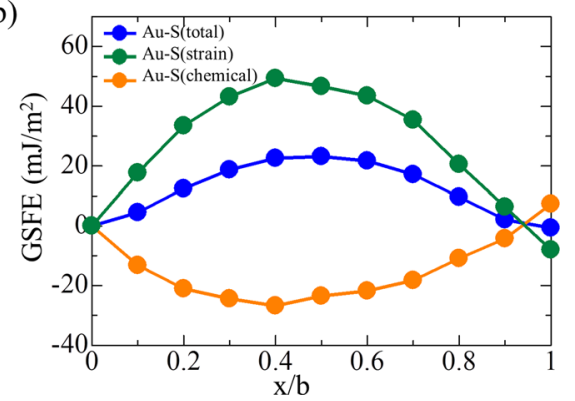

FIG. 5. General stacking fault energy (GSFE) curves by first principles shear test simulations; (a) GSFE curves for Au and Au-S cells, in which sharing is performed at the nearest plane and the second nearest plane of the Au-S cell and (b) GSFE curves related to strain effects and chemical effects for shearing at the nearest plane for the Au-S cell. In the GSFE curves, $x$ is the displacement and $b$ is the Burgers vector of a partial dislocation for Au. The ultimate stacking fault energy (USFE) for slip at the nearest plane for the Au-S cell is much lower than that for the Au cell, although a reduction in USFE for slip at the second nearest plane for the $\mathrm{Au}-\mathrm{S}$ cell is minor. The reduction in USFE is due to the chemical effects of Au-S, not the strain effects.

all the Au surface is covered by the SAMs due to the weak interaction between $\mathrm{MHO}$ and Au surface. ${ }^{45}$

In conclusion, the MHO SAM-modified nanoporous $\mathrm{Au}$ showed lower hardness than the non-modified nanoporous $\mathrm{Au}$. The activation volume of both the SAM-modified nanoporous $\mathrm{Au}$ and non-modified nanoporous $\mathrm{Au}$ was low, indicating that events related to a short range play an important role in deformation of nanoporous $\mathrm{Au}$, regardless of whether the nanoporous $\mathrm{Au}$ was modified with SAMs. It was suggested from the first principles shear test simulations that the lower hardness for the SAM-modified nanoporous $\mathrm{Au}$ is because movement of dislocation endpoints at the surface is facilitated by chemical effects of $\mathrm{Au}-\mathrm{S}$ bonding. Fellows.

N.M. acknowledges support from Grant-in-Aid for JSPS

${ }^{1}$ A. Wittstock, B. Neumann, A. Schaefer, K. Dumbuya, C. Kübel, M. M. Biener, V. Zielasek, H.-P. Steinrück, J. M. Gottfried, J. Biener, A. Hamza, and M. Bäumer, J. Phys. Chem. C 113, 5593 (2009).

${ }^{2}$ J. Biener, A. Wittstock, L. A. Zepeda-Ruiz, M. M. Biener, V. Zielasek, D. Kramer, R. N. Viswanath, J. Weissmüller, M. Bäumer, and A. V. Hamza, Nat. Mater. 8, 47 (2009).

${ }^{3}$ D. Kramer, R. N. Viswanath, and J. Weissmüller, Nano Lett. 4, 793 (2004).

${ }^{4}$ J. Biener, A. M. Hodge, A. V. Hamza, L. M. Hsiung, and J. H. Satcher, Jr., J. Appl. Phys. 97, 024301 (2005).

${ }^{5}$ C. A. Volkert, E. T. Lilleodden, D. Kramer, and J. Weissmüller, Appl. Phys. Lett. 89, 061920 (2006).

${ }^{6}$ J. Biener, A. M. Hodge, J. R. Hayes, C. A. Volkert, L. A. Zepeda-Ruiz, A. V. Hamza, and F. F. Abraham, Nano Lett. 6, 2379 (2006).

${ }^{7}$ A. M. Hodge, J. Biener, J. R. Hayes, P. M. Bythrow, C. A. Volkert, and A. V. Hamza, Acta Mater. 55, 1343 (2007).

${ }^{8}$ M. Hakamada and M. Mabuchi, Scr. Mater. 56, 1003 (2007).

${ }^{9}$ L. Zuo and A. H. W. Ngan, Philos. Mag. Lett. 86, 355 (2006).

${ }^{10}$ J. Diao, K. Gall, M. L. Dunn, and J. A. Zimmerman, Acta Mater. 54, 643 (2006).

${ }^{11}$ A. M. Hodge, R. T. Doucette, M. M. Biener, J. Biener, O. Cervantes, and A. V. Hamza, J. Mater. Res. 24, 1600 (2009).

${ }^{12}$ F. Malem and D. Mandler, Anal. Chem. 65, 37 (1993).

${ }^{13}$ M. Strattmann, Adv. Mater. 2, 191 (1990).

${ }^{14}$ A. Ulman, Thin Solid Films 273, 48 (1996).

${ }^{15}$ J. Chen, M. A. Reed, A. M. Rawlett, and J. M. Tour, Science 286, 1550 (1999).
${ }^{16}$ C. Albonetti, S. Casalini, F. Borgatti, L. Florean, and F. Biscarini, Chem. Commun. 47, 8823 (2011).

${ }^{17}$ L. Costelle, P. Jalkanen, M. T. Räisänen, L. Lind, R. Nowak, and J. Räisänen, J. Appl. Phys. 110, 114301 (2011).

${ }^{18}$ W.-Y. Chang, T.-H. Fang, and C.-N. Fang, J. Phys. Chem. B 113, 14994 (2009).

${ }^{19}$ H. Hu, L. Reven, and A. Rey, J. Phys. Chem. B 117, 12625 (2013).

${ }^{20}$ T.-H. Fang, W.-Y. Chang, S.-J. Lin, and C.-N. Fang, J. Colloid Interface Sci. 345, 19 (2010).

${ }^{21}$ M. Aponte-Roman, B. Mohanty, and A. B. Mann, Acta Mater. 68, 52 (2014).

${ }^{22}$ A. B. Steel, T. M. Herne, and M. J. Tarlov, Anal. Chem. 70, 4670 (1998).

${ }^{23}$ M. Pita, C. Gutierrez-Sanchez, D. Olea, M. Velez, C. Garcia-Diego, S. Shleev, V. M. Fernandez, and A. L. De Lacey, J. Phys. Chem. C 115, 13420 (2011).

${ }^{24}$ S. J. Clark, M. D. Segall, C. J. Pickard, P. J. Hasnip, M. I. J. Probert, K. Refson, and M. C. Payne, Z. Kristallogr. 220, 567 (2005).

${ }^{25}$ P. Hohenberg and W. Kohn, Phys. Rev. 136, B864 (1964).

${ }^{26}$ W. Kohn and L. Sham, Phys. Rev. 140, A1133 (1965).

${ }^{27}$ D. Vanderbilt, Phys. Rev. B 41, 7892 (1990).

${ }^{28}$ H. J. Monkhhost and J. D. Pack, Phys. Rev. B 13, 5188 (1976).

${ }^{29}$ O. N. Mryasov, Y. N. Gronostyrev, and A. J. Freeman, Phys. Rev. B 58, 11927 (1998).

${ }^{30}$ G. Lu, N. Kioussis, V. V. Bulatov, and E. Kaxiras, Phys. Rev. B 62, 3099 (2000).

${ }^{31}$ D. J. Siegel, Appl. Phys. Lett. 87, 121901 (2005).

${ }^{32}$ S. Kibey, J. B. Liu, D. D. Johnson, and H. Sehitoglu, Appl. Phys. Lett. 89, 191911 (2006).

${ }^{33}$ D. Finkenstadt and D. D. Johnson, Phys. Rev. B 73, 024101 (2006).

${ }^{34}$ M. Yuasa, Y. Chino, and M. Mabuchi, J. Mater. Res. 29, 2576 (2014).

${ }^{35}$ R. Wu, A. J. Freeman, and G. B. Olson, Science 265, 376 (1994).

${ }^{36}$ W. T. Geng, A. J. Freeman, R. Wu, C. B. Geller, and J. E. Raynolds, Phys. Rev. B 60, 7149 (1999).

${ }^{37}$ J. S. Braithwaite and P. Rez, Acta Mater. 53, 2715 (2005).

${ }^{38}$ A. Y. Lozovoi, A. T. Paxton, and M. W. Finnis, Phys. Rev. B 74, 155416 (2006).

${ }^{39}$ A. Y. Lozovoi and A. T. Paxton, Phys. Rev. B 77, 165413 (2008).

${ }^{40}$ L. Lu, R. Schwaiger, Z. W. Shan, M. Dao, K. Lu, and S. Suresh, Acta Mater. 53, 2169 (2005).

${ }^{41}$ H.-J. Jin, L. Kurmanaeva, J. Schmauch, H. Rösner, Y. Ivanisenko, and J. Weissmüller, Acta Mater. 57, 2665 (2009).

${ }^{42}$ H.-J. Jin and J. Weissmüller, Science 332, 1179 (2011).

${ }^{43}$ F. Tielens and E. Santos, J. Phys. Chem. C 114, 9444 (2010).

${ }^{44}$ M. Hakamada, M. Takahashi, T. Furukawa, K. Tajima, K. Yoshimura, Y. Chino, and M. Mabuchi, Phys. Chem. Chem. Phys. 13, 12277 (2011).

${ }^{45}$ Y.-F. Liu, Y.-C. Yang, and Y.-L. Lee, Nanotechnology 19, 065609 (2008). 